RESEARCH NOTE

\section{Intestinal Parasites in AIDS and +HIV Patients in Uberlândia, Minas Gerais, Brazil}

\section{Julia Maria Costa-Cruz $/^{+}$, Marcelo Simão Ferreira*, Iris Ricardo Rossin $^{++}$}

Departamento de Patologia *Departamento de Clínica Médica, Centro de Ciências Biomédicas, Universidade Federal de Uberlândia, Av. Pará 1720, 38400-902 Uberlândia, MG, Brasil

\begin{abstract}
Key words: intestinal parasites - Acquired Immunodeficiency Syndrome - Human Immunodeficiency Virus
\end{abstract}

In spite of biomedical advances, parasitic disease continues to exist and represent an exemple of complex interaction between parasite and host (OPAS 1985, publicación 1). Many patients infected by the Human Immunodeficiency Virus (HIV) because of their sexual practices, are predisposed to enteric infections as well as to traditional sexually transmitted diseases (SC Phillips et al. $1981 \mathrm{~N}$ Engl J Med 305: 603-606). Intestinal parasites in HIV infected patients, have been reported mainly in USA and Africa (PD Smith et al. 1988 Am Inter Med 108: 328-333, BE Laughon et al. 1988 Gastroenterol 94: 984-993, MA Gomez Moraes et al. 1995 Trop Med Parasitol 46: 109114).

In Brazil, the occurence of intestinal parasites in HIV patients was reported particullarly in the states of Rio de Janeiro and São Paulo (JR Coura 1987 J Bras Med 53: 42-54, RMDS Dias et al. 1988 Rev Inst Adolfo Lutz 48: 63-67, H Moura et al. 1989 Mem Inst Oswaldo Cruz 84: 527-533, RMDS Dias et al. 1992 Rev Inst Med Trop São Paulo 34: 1517).

This study was undertaken to contribute to the knowledge of the occurence of intestinal parasites in AIDS and +HIV patients in Uberlândia, in the

\footnotetext{
${ }^{+}$Corresponding author. Fax: +55-34-218.2333

${ }^{++}$Bolsista PET/CAPES/Medicina/UFU

Received 26 February 1996

Accepted 16 August 1996
}

State of Minas Gerais, Southeast region of Brazil. A retrospective analysis of medical files was made of 291 patients who were attended in the Infirmary of Infectious and Parasitic Diseases of the Clinical Hospital at Federal University of Uberlândia (HCUFU), during the period of January 1990 to December 1994. Of these patients 238 were AIDS patients and 53 were + HIV. Files of attended patients (897) were analized as a control group in the Clinical Medical Ambulatory of HC-UFU and all these patients did parasitologic examination in feces in the same period. The data was randomally considering the total number of patients month by month during the work period. The results were obtained through the examination of feces and submitted to statistic analisys following a normal distribution curve. The group of AIDS patients was compared to the +HIV and control group adopting a level of alfa significance equal to $0.05(5 \%)$.

The fecal material of the 1,188 patients was collected in plastic flask, containing $10 \mathrm{ml}$ of MIF, for the realization of the method of MIFC. In the cases of 108 patients with AIDS and diarrheic feces, $10 \mathrm{ml}$ of formol $40 \%$, was also used to research of Cryptosporidium sp. or Isospora belli by Kinyoun coloration. The methods of MIFC and coloration were both made in the laboratory of clinical analysis of HC-UFU (Baermman-Moraes method is not a routine in this laboratory).

As result of this research 39 (16.4\%) patients were diagnosed with parasites in the AIDS group; of these, $78.9 \%$ were male and $21.1 \%$ were female. Their ages varied between 4 and 60 years; $94.7 \%$ were from the State of Minas Gerais and 5.3\% from the State of São Paulo.

In the group of $+\mathrm{HIV}$ patients there were 5 $(9.4 \%)$ patients with parasites; $80 \%$ were male and $20 \%$ female. Their ages varied between 22 and 33 years; $80 \%$ were from the State of Minas Gerais and $20 \%$ from the State of São Paulo.

In the control group there were 69 (7.7\%) patients with parasites; $58.7 \%$ were male and $41.3 \%$ were female. Their ages varied between 1 and 76 years; $90.6 \%$ were from the State of Minas Gerais, $6.7 \%$ from the State of São Paulo and $2.7 \%$ from the State of Goiás.

The Table shows the occurrence of intestinal parasites detected by the method of MIFC or Kinyoun in AIDS, +HIV patients and control group.

In the AIDS patients group there were 32 $(82.1 \%)$ cases of monoparasitism, $5(12.8 \%)$ cases of biparasitism and $2(5.1 \%)$ cases of poliparasitism. The associations found are the following: Strongyloides stercoralis and Hymenolepis nana (1 case), S. stercoralis and Giardia intestinalis (1 case), S. stercoralis and Cryptosporidium sp. (1 
case), Ascaris lumbricoides and Cryptosporidium sp. (1 case), A. lumbricoides and hookworm (1 case), Cryptosporidium sp., hookworm and Entamoeba histolytica (1case) and S. stercoralis, hookworm, E. histolytica and Trichuris trichiura (1 case).

In the + HIV patients group there were 5 cases of monoparasitism. In the control group there were $65(94.2 \%)$ cases of monoparasitism, $3(4.3 \%)$ cases of biparasitism and 1 case $(1.5 \%)$ of poliparasitism. The associations found were: $G$. intestinalis and $H$. nana ( 2 cases), hookworm and $S$. stercoralis (1 case) and $T$. trichiura, $A$. lumbricoides and $S$. stercoralis (1 case).

The statistical analysis showed significance when compared the occurrence of $S$. stercoralis in AIDS patients group and in the control group (calculated $\mathbf{Z}=2.71$ to critical $\mathbf{Z}=1.645$ ). The differences for the rest of the parasites were not significant in comparison to the control group. There were no significant statistical difference in comparison to the + HIV group of patients.

A significant statistical difference was observed in comparison to the number of patients with more than one parasite in reference to the group of pa- tients with AIDS and in the control group (calculated $\mathbf{Z}=3.92$ to critical $\mathbf{Z}=1.645$ ).

It was demonstrated that the occurrence of intestinal parasitic diseases in AIDS patients was higher than the observed in +HIV patients and the control group. This difference was significant when compared to the occurrence of $S$. stercoralis in AIDS group and control group. It was also observed that patients with more than one parasite are more frequently encountered among AIDS individuals, the difference is significant in relation to the control group. The importance of research in Cryptosporidium sp. should be emphasized as well as the routine diagnosis in patients that reveal diarrhea. The frequency of S. stercoralis is also important, even though the specific parasitologic method for research in helminths larvae in feces were not used in the routine of the laboratory.

Acknowledgements: to Vanderli Anacleto de Campos (Dept. of Mathematics at Educational Fundation of Ituiutaba) for stastistical assistence, Ademir Barsanulfo de Moraes, chief of the Laboratory of Clinical Analysis, Clinical Hospital, Federal University of Uberlândia, and Maria da Consolação Nogueira de Souza for technical assistance.

TABLE

Intestinal parasites in AIDS, +HIV patients and control group in Uberlândia, MG, Brazil

\begin{tabular}{|c|c|c|c|c|c|c|}
\hline \multirow[b]{2}{*}{ Parasites } & \multicolumn{2}{|c|}{ AIDS } & \multicolumn{2}{|c|}{$+\mathrm{HIV}$} & \multicolumn{2}{|c|}{ Control group } \\
\hline & Frequences & $\begin{array}{c}\text { no. positive/ } \\
\text { no. tested }\end{array}$ & Frequences & $\begin{array}{c}\text { no. positive/ } \\
\text { no. tested }\end{array}$ & Frequences & $\begin{array}{r}\text { no. positive/ } \\
\text { no. tested }\end{array}$ \\
\hline Cryptosporidium sp. & $13.0 \%$ & $(15 / 108)$ & $\longrightarrow$ & - & $\longrightarrow$ & - \\
\hline Strongyloides stercoralis & $3.8 \%$ & $(09 / 238)$ & $3.8 \%$ & $(02 / 53)$ & $1.2 \%$ & $(11 / 897)$ \\
\hline Giardia intestinalis & $3.4 \%$ & $(08 / 238)$ & $1.9 \%$ & $(01 / 53)$ & $3.8 \%$ & $(34 / 897)$ \\
\hline Isospora belli & $2.8 \%$ & $(03 / 108)$ & - & - & $\longrightarrow$ & - \\
\hline Entamoeba histolytica & $2.1 \%$ & $(05 / 238)$ & $1.9 \%$ & $(01 / 53)$ & $0.9 \%$ & $(08 / 897)$ \\
\hline Hookworm & $2.1 \%$ & $(05 / 238)$ & $1.9 \%$ & $(01 / 53)$ & $1.3 \%$ & $(12 / 897)$ \\
\hline Ascaris lumbricoides & $0.8 \%$ & $(02 / 238)$ & 0 & $(00 / 53)$ & $0.5 \%$ & $(05 / 897)$ \\
\hline Hymenolepis nana & $0.4 \%$ & $(01 / 238)$ & 0 & $(00 / 53)$ & $0.4 \%$ & $(04 / 897)$ \\
\hline Schistosoma mansoni & $0.4 \%$ & $(01 / 238)$ & 0 & $(00 / 53)$ & $0.2 \%$ & $(02 / 897)$ \\
\hline Trichuris trichiura & $0.4 \%$ & $(01 / 238)$ & 0 & $(00 / 53)$ & $0.5 \%$ & $(05 / 897)$ \\
\hline Enterobius vermicularis & 0 & $(00 / 238)$ & 0 & $(00 / 53)$ & $0.2 \%$ & $(02 / 897)$ \\
\hline
\end{tabular}

$=$ not tested 